\title{
Clinically diagnosed iron and iodine deficiencies and disorders in the entire population of US military service members from 1997 to 2015
}

\author{
Joseph J Knapik 1,2,*, Emily K Farina ${ }^{1}$, Victor L Fulgoni III ${ }^{1,2}$ and Harris R Lieberman ${ }^{1}$ \\ ${ }^{1}$ Military Nutrition Division, US Army Research Institute of Environmental Medicine, Natick, MA 01760, USA: \\ ${ }^{2}$ Henry M Jackson Foundation for the Advancement of Military Medicine, Bethesda, MD, USA
}

Submitted 26 May 2020: Final revision received 24 December 2020: Accepted 1 February 2021: First published online 5 February 2021

\begin{abstract}
Objective: Iron and/or iodine deficiencies can have multiple serious adverse health outcomes, but examination of incidence rates of these deficiencies has rarely been conducted in any large population. This study examined incidence rates, temporal trends and demographic factors associated with medically diagnosed iron and iodine deficiencies/disorders in US military service members (SM).

Design: The Defense Medical Epidemiological Database (DMED) was queried for medical visits of active duty SM to obtain specific International Classification of Diseases, Version 9, codes involving clinically diagnosed iron and iodine deficiencies/disorders.

Setting: Analysis of existing database (DMED).

Participants: Entire population of US military SM from 1997 to 2015 (average $n$ per year =1 382 266, 15\% women).

Results: Overall incidence rates for iron and iodine were 104 and 36 cases/100 000 person-years, respectively. Over the 19-year period, rates for iron disorders increased steadily (108\% for men, $177 \%$ for women). Rates for iodine disorders also increased steadily for men (91\%), but, for women, there was an initial rise followed by a later decline. Overall, women's rates were 12 and 10 times higher than men's for iron and iodine, respectively. Compared with whites, blacks and those of other races had higher rates of deficiencies of both minerals. Incidence rates for iodine deficiency increased substantially with age.

Conclusions: The overall incidence of clinically diagnosed iron and iodine deficiency among SM was low, but increased over the 19 years examined, and certain demographic groups were at significantly greater risk. Given the unexpected increases in incidence of these mineral disorders, increased surveillance may be appropriate.

Clinical Trial Registration No. ISRCTN58987177 (http//:www.isrctn.com/ ISRCTN58987177)
\end{abstract}

Despite highly successful efforts to improve nutrition in the US Armed Forces ${ }^{(1-4)}$, mineral deficiencies can still be found among some US military service members (SM) and are also present in some of the civilian populations ${ }^{(5,6)}$. Prescriptions ordered by military health care providers for several mineral preparations increased from 2005 to 2013 and differed by specific demographic groups ${ }^{(7-9)}$, suggesting that military health care providers determined that mineral supplementation was important to maintain the health of some SM. One mineral of concern in SM is iron, a critical micronutrient incorporated into proteins and enzymes that is important for physical, cognitive and immune functioning ${ }^{(10,11)}$ and is deficient in significant numbers of $\mathrm{SM}^{(12,13)}$ and many civilians especially women of childbearing age ${ }^{(5)}$. In longitudinal studies, iron status deteriorated during deployment among Special Operations soldiers ${ }^{(14)}$, as well as during Basic Combat Training, and was associated with a decline in aerobic performance in the latter group ${ }^{(13,15)}$. The prevalence of iron deficiency and iron deficiency anaemia was

*Corresponding author: Email joseph.j.knapik.ctr@mail.mil

(c) US Army Research Institute of Environmental Medicine, 2021. To the extent this is a work of the US Government, it is not subject to copyright protection within the United States. Published by Cambridge University Press on behalf of The Nutrition Society. This is an Open Access article, distributed under the terms of the Creative Commons Attribution-NonCommercial-ShareAlike licence (http://creativecommons.org/licenses/by-nc-sa/4. 0/), which permits non-commercial re-use, distribution, and reproduction in any medium, provided the same Creative Commons licence is included and the original work is properly cited. The written permission of Cambridge University Press must be obtained for commercial re-use. 
$13 \%$ and $33 \%$ among female Army personnel in Basic Combat Training and Army Advanced Individual Training, respectively, when their iron status was assessed using standard laboratory measures including iron status indicator assays and a microparticle enzyme immunoassay ${ }^{(12)}$.

Low iodine intake causes goitre and hypothyroidism since iodine is an essential component of thyroid hormones $^{(16,17)}$. Thyroid hormones are critical for the regulation of metabolism, and symptoms of thyroid deficiency include fatigue, weight gain, muscle pain and kidney dysfunction $^{(18)}$. Over 10000 cases of thyroid disorders were diagnosed in the US military in the period 2008-2017, an incidence rate of 7·4/10,000 person-years $(p-y)^{(19)}$.

In light of the reports cited above, the purpose of this investigation was to examine incidence rates, demographics and secular trends associated with clinically diagnosed iron and iodine disorders in the entire US SM population from 1997 to 2015 as documented in medical records. To date, there has been no large epidemiological investigation that examined the scope of this problem in military or civilian populations to the best of our knowledge. We focused on disorders associated with low dietary intake of iron and iodine since they are of clinical significance and are well documented by International Classification of Diseases, 9th Revision, Clinical Modification (ICD-9) codes.

\section{Methods}

Defense Medical Epidemiological Database (DMED) is a comprehensive surveillance system containing inpatient and outpatient medical encounters of all uniformed military personnel and includes demographic data of SM. The number of medically diagnosed cases of any single medical problem can be determined based on ICD-9 codes. The yearly incidence rates of these medical problems can also be obtained since the DMED provides the number of uniformed personnel serving per year. Data can be grouped by a limited number of demographics, including sex, age, race and military service branch.

Participants in this study were the entire population of the US military (Army, Navy, Marine Corps and Air Force) serving between 1997 and 2015. For iron, only ICD-9 codes indicative of iron deficiency anaemia were selected since these are related to low iron intake. Thus, for iron, ICD-9 codes included 280.1, 280.8 and 280.9. An additional code (275.0, disorders of iron metabolism) was not selected because it primarily relates to disorders associated with excessive iron storage (e.g. hemochromatosis, pigmentary cirrhosis of liver). For iodine, ICD-9 codes included $240 \cdot 0$ and $240 \cdot 9$. There were several ICD-9 codes (240-246 series) indicative of disorders of the thyroid gland but only simple and unspecified goitre is related to low dietary intake ${ }^{(17)}$. Thyroid gland-related ICD-9 codes that were not included related to conditions of decreased iodine production (241 series), iodine overproduction (242 series) and low production due to acquired or pathological conditions (244-246 series).

The number of first occurrences and primary diagnosis for each individual ICD-9 code were obtained from the DMED for each year from 1997 through 2015 and summed for the selected ICD-9 codes indicating iron and iodine disorders. If a SM had one or more ICD-9 code indicative of one of the mineral disorders, they were included as an incidence case for that particular disorder. Cases involving both hospitalisations and outpatient visits were included. The incidence rate was calculated as the number of new cases of a particular category (grouping) of ICD-9 codes divided by the population for that year and multiplied by 100000 to obtain cases/100 000 p-y (i.e. (number of new cases/population at risk for the year) $\times 100000)$. Data were plotted by year for the entire male and female cohorts. Linear trend lines were displayed on the graphs along with the equation describing the trend line, variance accounted for $\left(r^{2}\right)$ and standard error of the estimate. In developing the regression equation, years were indicated by sequential numbers $(1,2,3$, etc.) rather than the actual years so that the intercept was at the first year (1997). Percentage changes in the incidence rates of mineral disorders from 1997 to 2015 were calculated as ((incidence rate in 2015 - incidence rate 1997)/incidence rate in 1997) $\times 100 \%$.

Cases were also obtained by sex, age (<20, 20-24, 25-29, 30-34, 35-39, $\geq 40$ years), race (white, black, other) and military service (Army, Navy, Air Force, Marine Corps) with the corresponding populations. Incidence rates (cases/ 100000 p-y) were calculated for each demographic stratum in both mineral categories. The risk of a mineral disorder was compared across the strata with a referent level of the demographic selected (indicated by an incidence rate ratio $=1 \cdot 00$ ), and comparisons were made to that level. The Open Source Epidemiologic Calculator was used to determine incident rate ratios with $95 \% \mathrm{CI}^{(20)}$. Power analysis was not conducted since the study involved the entire population of SM.

\section{Results}

Table 1 presents descriptive statistics on the demographics of the SM population for the entire 19-year period from 1997 through 2015 . The majority of the population was composed of men, whites and those aged 20-29 years. Nonetheless, other demographic groups were also well represented. For example, on average, there were over 200000 women and over 250000 blacks in the population per year.

Table 2 presents the aggregate number of cases and incidence rates for each ICD-9 code and code groupings for both iron and iodine for the entire period. The most commonly diagnosed iron disorder was 'iron deficiency anemia, unspecified' (ICD-9 code 280.9) accounting for $85 \%$ of the cases. The most commonly diagnosed iodine 
Iron and iodine disorders in US Military

3189

Table 1 Descriptive Statistics on Demographics of Service Member Population, 1997-2015

\begin{tabular}{|c|c|c|c|c|}
\hline Demographic variables & Strata & Mean & SD & $\begin{array}{l}\text { Proportion of } \\
\text { demographic } \\
\text { variable (\%) }\end{array}$ \\
\hline Total population & & 1382266 & 30987 & $100 \cdot 0$ \\
\hline \multirow[t]{2}{*}{ Sex } & Men & 1181011 & 29728 & 85.4 \\
\hline & Women & 201255 & 5378 & $14 \cdot 6$ \\
\hline \multirow[t]{6}{*}{ Age group } & $<20$ years & 102003 & 16856 & $7 \cdot 4$ \\
\hline & 20-24 years & 447211 & 23715 & $32 \cdot 4$ \\
\hline & $25-29$ years & 305918 & 27547 & $22 \cdot 1$ \\
\hline & $30-34$ years & 210145 & 13502 & $15 \cdot 2$ \\
\hline & $35-40$ years & 174833 & 18642 & 12.6 \\
\hline & $>40$ years & 142156 & 7758 & $10 \cdot 3$ \\
\hline \multirow[t]{3}{*}{ Race } & White & 945680 & 28412 & $68 \cdot 4$ \\
\hline & Black & 250526 & 19488 & $18 \cdot 1$ \\
\hline & Other & 186060 & 8247 & 13.5 \\
\hline \multirow[t]{4}{*}{ Military Service } & Army & 506209 & 31422 & $36 \cdot 6$ \\
\hline & Navy & 348099 & 25871 & $25 \cdot 2$ \\
\hline & Air Force & 344083 & 19850 & 24.9 \\
\hline & Marine Corps & 183875 & 11663 & $13 \cdot 3$ \\
\hline
\end{tabular}

Table 2 Cases and incidence rates for iron and iodine disorders among US Military Personnel, 1997-2017. Total incidences for each disorder and each individual ICD-9 code

\begin{tabular}{|c|c|c|c|c|c|c|}
\hline \multirow[b]{2}{*}{ Mineral disorder (ICD-9 code) } & \multicolumn{2}{|c|}{ Outpatient } & \multicolumn{2}{|c|}{ Inpatient } & \multicolumn{2}{|c|}{ Total } \\
\hline & Cases $(n)$ & $\begin{array}{c}\text { Incidence rate } \\
\text { (cases/100 000 } \\
\text { person-year) }\end{array}$ & Cases $(n)$ & $\begin{array}{c}\text { Incidence rate } \\
\text { (cases/100 } 000 \\
\text { person-year) }\end{array}$ & Cases $(n)$ & $\begin{array}{c}\text { Incidence rate } \\
\text { (cases/100 000 } \\
\text { person-year) }\end{array}$ \\
\hline Iron $(280 \cdot 1,280 \cdot 8,280 \cdot 9)$ & 26955 & $102 \cdot 63$ & 426 & $1 \cdot 62$ & 27381 & $104 \cdot 26$ \\
\hline $\begin{array}{l}\text { Iron deficiency anaemia secondary } \\
\text { to dietary iron intake }(280 \cdot 1)\end{array}$ & 2698 & $10 \cdot 27$ & 3 & 0.01 & 2701 & $10 \cdot 28$ \\
\hline $\begin{array}{l}\text { Other specified iron deficiency } \\
\text { anaemias }(280 \cdot 8)\end{array}$ & 1438 & 5.48 & 16 & 0.06 & 1454 & $5 \cdot 54$ \\
\hline $\begin{array}{l}\text { Iron deficiency anaemia, } \\
\text { unspecified (280.9) }\end{array}$ & 22819 & $86 \cdot 89$ & 407 & 1.55 & 23226 & $88 \cdot 44$ \\
\hline lodine (Goitre) $(240.0,240.9)$ & 9403 & $35 \cdot 80$ & 113 & 0.43 & 9516 & $36 \cdot 23$ \\
\hline Goitre, specified as simple (240.0) & 1738 & $6 \cdot 62$ & 9 & 0.03 & 1747 & $6 \cdot 65$ \\
\hline Goitre, unspecified (240.9) & 7665 & $29 \cdot 19$ & 104 & 0.40 & 7769 & $29 \cdot 58$ \\
\hline
\end{tabular}

deficiency was 'goiter, unspecified' (ICD-9 code 240.9), accounting for $82 \%$ of cases. Hospitalisations accounted for only $1.5 \%$ of cases (539/36 897). The overall incidence rate for both mineral disorders combined was 140.5 cases/ 100000 p-y.

Figure 1 presents the secular trends in iron and iodine disorders by sex. From 1997 to 2015, iron disorder incidence rates (Fig. 1a) for men increased from 23.6 to $49 \cdot 1$ cases $/ 100000 \mathrm{p}-\mathrm{y}$ (108\% increase), at an approximate rate (based on linear regression) of 2.0 cases/100 000 p-y. In this same period, iron disorder incidence rates (Fig. 1b) for women increased from 169.4 to 469.7 cases/100 000 p-y (177\% increase), at an approximate rate of 20 cases/ 100000 p-y. From 1997 to 2015, iodine disorder incidence rates in men (Fig. 1c) increased from 8.0 to 15.3 cases/ 100000 p-y (91\% increase), at an approximate rate of 0.8 cases $/ 100000 \mathrm{p}-\mathrm{y}$. Iodine disorder incidence rates in women (Fig. 1 d) increased from 113.3 cases/100 000 p-y in 1997, reached a peak in 2007 (193.0 cases/100 000 p-y) and then declined to $137 \cdot 3$ cases/100 000 p-y by 2015.
Table 3 presents mineral disorders by demographic characteristics. Iron disorder incidence rates were about 12 times higher among women compared with men and were highest in the youngest and oldest age groups compared with other age groups. Higher rates were evident among blacks and those of other races compared with whites; rates were higher in the Army and Air Force than in the Navy and Marine Corps. Iodine disorder incidence rates were about 10 times higher among women compared with men and increased with age in both sexes. Rates were higher among blacks compared with whites and other races and were higher in the Air Force and Army compared with the Navy and Marine Corps.

\section{Discussion}

This study provides the first comprehensive examination of incidence rates of iron and iodine disorders in the entire US military population. Over the 19-year period examined, 
(a) Iron Disorders (Men)

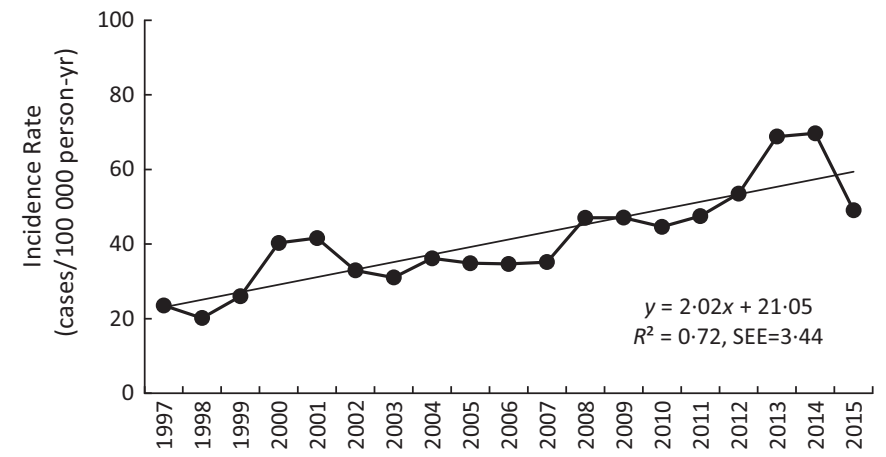

(c) lodine Disorders (Men)

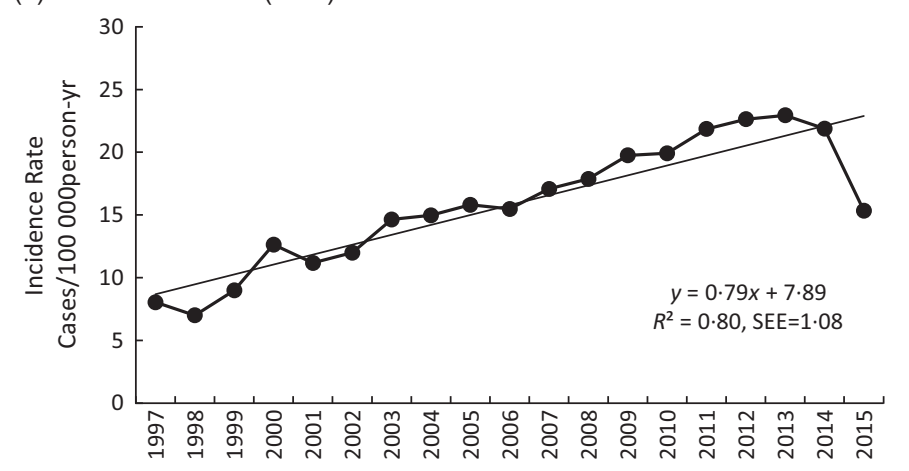

(b) Iron Disorders (Women)

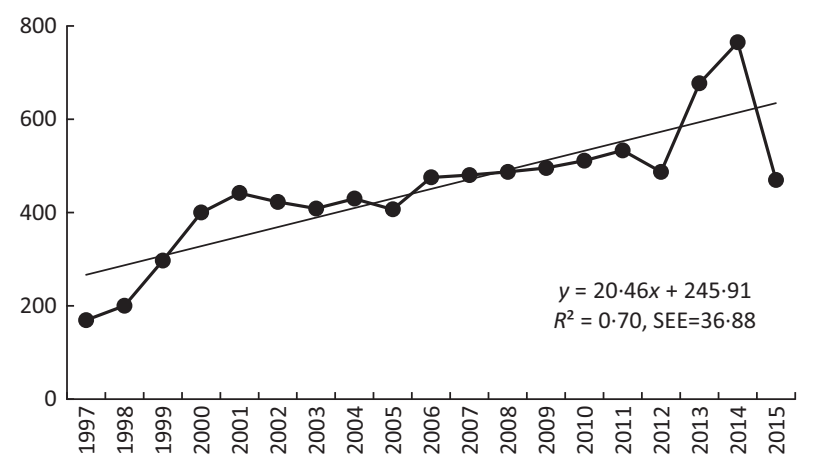

(d) lodine Disorders (Women)

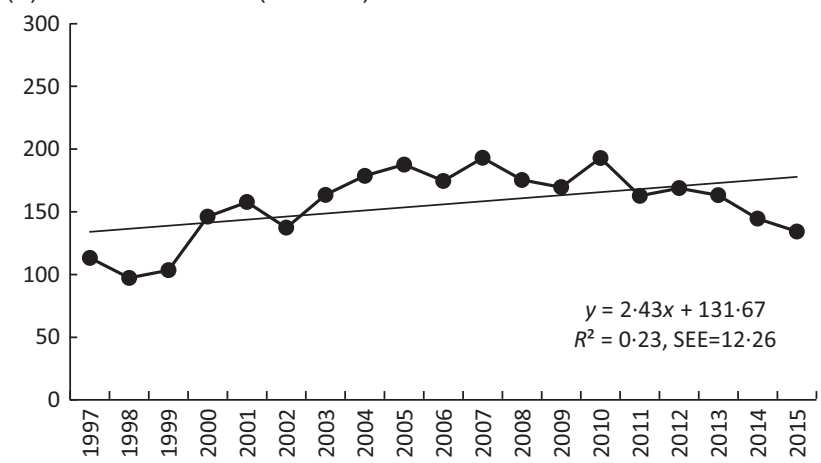

Fig. 1 Incidence of iron and iodine disorders in US Military Service Members 1997-2015. (a) Iron disorders (men); (b) iron disorders (women); (c) iodine disorders (men); (d) iodine disorders (women). Straight lines are best fit linear regression lines described by equations on graphs (SEE = standard error of estimate)

the incidence of clinically diagnosed iron and iodine deficiencies was low, only 104 and 36 cases/100 000 p-y, respectively. Nonetheless, among both men and women, incidence rates for iron increased dramatically over time. In contrast, while iodine disorder rates increased steadily among men, in women they increased in the early years examined followed by a more recent gradual decline. Overall, women had much higher incidence rates than men for both mineral disorders. Iron disorder rates were highest among the youngest and oldest age groups, but rates for iodine increased with age. For both iron and iodine, black SM had higher incidence rate than white SM and rates were higher among Army and Air Force SM compared with Navy and Marine Corps SM.

A distinction is typically made in the literature between iron deficiency, where iron stores decline and transport is compromised $^{(21)}$, and iron deficiency anaemia, where ironcontaining proteins (especially $\mathrm{Hb}$ ) decline and fall below a specific cut point ${ }^{(22)}$. Iron deficiency is the most common micronutrient deficiency worldwide ${ }^{(23)}$. In the Global Burden of Diseases, Injuries, and Risk Factors Study involving 328 diseases in 195 countries, iron deficiency anaemia was one of the five most common medical problems contributing to years individuals lived with a disability ${ }^{(24)}$. In the USA, the RDA for iron for 19-50-year-old women is over twice that of comparably aged men, $18 \mathrm{mg} / \mathrm{d}$ compared with $8 \mathrm{mg} / \mathrm{d}$, primarily due to menstrual blood loss ${ }^{(25)}$. In general agreement with the present study, a report assessing iron deficiency anaemia in the entire US Armed Forces population from 2002 to 2011 found an increase in the incidence rate over time, as well as higher risk in women, the youngest ( $<20$ year) and oldest ( $>40$ years) age groups, and among black $\mathrm{SM}^{(26)}$.

The prevalence of iron deficiencies in the US military has been shown to differ depending on the stage of military training. Among a cohort of Army women followed longitudinally for over 6 months and based on a comprehensive battery of laboratory tests, the prevalence of iron deficiency was $13 \%$ on entry to the Army, increased to $33 \%$ near the end of basic training and decreased to $10 \%$ in a post-basic training assignment; comparable values for iron deficiency anaemia were 6, 21 and 5\%, respectively ${ }^{(12)}$. Iron status also declined among men during basic training ${ }^{(15)}$, and similar declines in iron status have been observed in Israeli and New Zealand military recruits during basic training ${ }^{(27-29)}$. When laboratory data are collected on SM, rates of deficiency are much higher than the diagnosed rates documented here, suggesting many SM, like the general population and especially women, are not being treated for iron deficiency ${ }^{(30)}$. Cases of iron disorders and the increase over time in both male and female SM documented in the present study are of considerable concern 
Table 3 Iron and iodine disorders among US Military Personnel by Demographic characteristics (1997-2015)

\begin{tabular}{|c|c|c|c|c|c|c|c|c|c|c|}
\hline \multirow[b]{2}{*}{ Disorder } & \multirow[b]{2}{*}{ Variable } & \multirow[b]{2}{*}{ Strata } & \multicolumn{4}{|c|}{ Men } & \multicolumn{4}{|c|}{ Women } \\
\hline & & & Cases(n) & $\begin{array}{c}\text { Incidence rate } \\
\text { (cases/100 } 000 \\
\text { person-years) }\end{array}$ & $\begin{array}{l}\text { Incident } \\
\text { rate ratio }\end{array}$ & $95 \% \mathrm{Cl}$ & Cases $(n)$ & $\begin{array}{l}\text { Incidence rate } \\
\text { (cases/100 } 000 \\
\text { person-years) }\end{array}$ & $\begin{array}{l}\text { Incident } \\
\text { rate ratio }\end{array}$ & $95 \% \mathrm{Cl}$ \\
\hline \multirow{14}{*}{ Iron } & Sex & & 9224 & $41 \cdot 1$ & 1.00 & & 18157 & $474 \cdot 84$ & 11.55 & $11 \cdot 27,11.84$ \\
\hline & Age, years & $<20$ & 1070 & 66.52 & 1.00 & & 3785 & 1148.80 & 1.00 & \\
\hline & & $20-24$ & 1957 & $27 \cdot 29$ & 0.41 & $0.38,0.44$ & 5552 & $419 \cdot 20$ & 0.36 & $0.35,0.38$ \\
\hline & & $25-29$ & 1365 & $27 \cdot 71$ & 0.42 & $0.38,0.45$ & 2748 & 310.03 & 0.27 & $0.26,0.28$ \\
\hline & & $30-34$ & 1168 & 33.87 & 0.51 & $0.47,0.55$ & 1932 & 355.19 & 0.31 & $0.29,0.33$ \\
\hline & & $35-39$ & 1430 & 48.98 & 0.74 & $0.68,0.80$ & 1954 & 485.74 & 0.42 & $0.40,0.45$ \\
\hline & & $\geq 40$ & 2234 & 94.52 & 1.42 & $1.32,1.53$ & 2186 & $648 \cdot 30$ & 0.56 & $0.54,0.59$ \\
\hline & Race & White & 5266 & $33 \cdot 19$ & 1.00 & & 6434 & 306.02 & 1.00 & \\
\hline & & Black & 2701 & $74 \cdot 15$ & $2 \cdot 23$ & $2 \cdot 13,2 \cdot 34$ & 9324 & 834.29 & $2 \cdot 73$ & $2 \cdot 64,2 \cdot 81$ \\
\hline & & Other & 1257 & $42 \cdot 89$ & 1.29 & $1.22,1.37$ & 2399 & 397.34 & & $1.24,1.36$ \\
\hline & Service & Army & 3499 & 42.43 & 1.00 & & 7081 & $516 \cdot 62$ & 1.00 & \\
\hline & & Navy & 2245 & 39.88 & 0.94 & $0.89,0.99$ & 4239 & $430 \cdot 21$ & 0.83 & $0.80,0.87$ \\
\hline & & Air Force & 2695 & 50.92 & $1 \cdot 20$ & $1 \cdot 14,1.26$ & 6129 & $492 \cdot 20$ & 0.95 & $0.92,0.99$ \\
\hline & & Marines & 785 & 24.00 & 0.57 & $0.52,0.61$ & 708 & 318.00 & 0.62 & $0.57,0.66$ \\
\hline \multirow[t]{14}{*}{ lodine } & Sex & & 3540 & $15 \cdot 78$ & 1.00 & & 5976 & $156 \cdot 28$ & 9.91 & $9.50,10.33$ \\
\hline & Age, years & $<20$ & 57 & 3.54 & 1.00 & & 175 & 53.11 & 1.00 & \\
\hline & & $20-24$ & 486 & $6 \cdot 78$ & 1.91 & $1.45,2.52$ & 1320 & 99.67 & 1.88 & $1.60,2.20$ \\
\hline & & $25-29$ & 631 & $12 \cdot 81$ & $3 \cdot 62$ & $2 \cdot 76,4 \cdot 74$ & 1449 & $163 \cdot 48$ & 3.08 & $2 \cdot 63,3.60$ \\
\hline & & $30-34$ & 616 & $17 \cdot 86$ & 5.04 & $3 \cdot 84,6 \cdot 61$ & 1088 & 200.03 & 3.77 & $3.21,4.42$ \\
\hline & & $35-39$ & 705 & $24 \cdot 15$ & $6 \cdot 82$ & $5.20,8.93$ & 966 & 240.04 & 4.52 & $3.85,5.31$ \\
\hline & & $\geq 40$ & 1045 & $44 \cdot 21$ & $12 \cdot 48$ & $9 \cdot 56,16.29$ & 978 & $290 \cdot 04$ & 5.46 & $4.65,6.41$ \\
\hline & Race & White & 2441 & $15 \cdot 39$ & 1.00 & & 2623 & $124 \cdot 76$ & 1.00 & \\
\hline & & Black & 696 & $19 \cdot 11$ & 1.24 & $1.14,1.35$ & 2619 & 234.34 & 1.88 & $1.78,1.98$ \\
\hline & & Other & 403 & $13 \cdot 75$ & 0.89 & $0.80,1.00$ & 734 & 121.57 & 0.97 & $0.90,1.06$ \\
\hline & Service & Army & 1330 & $16 \cdot 13$ & 1.00 & & 2175 & 158.69 & 1.00 & \\
\hline & & Navy & 702 & 12.47 & 0.77 & $0.71,0.84$ & 1213 & $123 \cdot 10$ & 0.78 & $0.72,0.83$ \\
\hline & & Air Force & 1150 & $21 \cdot 73$ & 1.35 & $1.25,1.46$ & 2377 & $190 \cdot 89$ & $1 \cdot 20$ & $1 / 0 \cdot 14,1 \cdot 28$ \\
\hline & & Marines & 358 & 10.94 & 0.68 & $0.60,0.76$ & 211 & 94.77 & 0.60 & $0.52,0.69$ \\
\hline
\end{tabular}


because of the well-known adverse effects of iron deficiency, especially iron deficiency anaemia, on physical ${ }^{(22)}$ and cognitive ${ }^{(31,32)}$ performance and the requirement for high levels of physical and cognitive capability for many military occupational tasks ${ }^{(33,34)}$. Once a deficiency is identified, widely accepted standards of care are available for determining the aetiology and providing treatment ${ }^{(35,36)}$.

Estimates of the population risk for iodine deficiency are typically based on urinary iodine concentrations (UIC), a reliable biomarker of recent iodine intake ${ }^{(38)}$. Low iodine intake is a major cause of goitre as demonstrated by many studies that found UIC is related to thyroid gland volume ${ }^{(17)}$, but other factors including genetic and environmental influences can be involved ${ }^{(39)}$. In the US military, goitre is a disqualifying medical conditions for entry into the military services $^{(40)}$, but conditions that arise after an individual is in service are treated as any other medical condition. Two previous studies examined incidence rates for goitre in the US Armed Forces from 2002 to $2011^{(41)}$ and from 2005 to $2017^{(19)}$. The early study ${ }^{(41)}$ found an increase in incidence rate over time for both men and women, while the later study $^{(19)}$ found increases among men, while rates declined among women. This is in general agreement with the present study which track rates over a longer continuous period: rates steadily increased among men, but increased then decreased among women. Also in agreement with the present study, previous US Armed Forces studies ${ }^{(19,41)}$ found substantially higher incidence rates for goitre among women and Air Force SM and that rates increased with age. The higher incidence rates in women may be related to the action of oestrogens on thyroid tissues ${ }^{(42)}$. It has also been suggested ${ }^{(41)}$ that the increased incidence rates of thyroid disease may have been due to increased testing for thyroid function disorders among SM due to psychiatric illnesses ${ }^{(43)}$ associated with conflicts in Iraq and Afghanistan. Several psychiatric disorders can have symptoms (depression, irritability) similar to thyroid dysfunction. The most recent declines in 2015 may reflect the fact that recently fewer SM are being deployed ${ }^{(44)}$.

In the US general population, iodine levels appear to be declining over time. Consecutive testing of UIC in NHANES indicated a $52 \%$ decline from NHANES I (1971-1974) to NHANES III (1988-1994), a stabilisation between NHANES III (1988-1994) and NHANES 2007-2008 and then a further $19 \%$ decline between NHANES 2007-2008 and NHANES 2013-2014 ${ }^{(45-49)}$. A different analytical technique was used in the earliest NHANES, but direct comparison of the two techniques demonstrated that results did not differ between the different assays ${ }^{(46)}$. The early decline in UIC has been attributed to a number of factors including efforts by the dietary industry to improve the quality of their product by reduced use of iodine to sterilise milk, reduced use of erythrosine (a dye containing iodine) in breakfast cereals, commercial bread manufacturers' replacement of iodine by bromine salts as a dough conditioner and lower intake of iodine-containing table salt ${ }^{(50,51)}$. The reasons for the more recent declines ${ }^{(47)}$ may be more related to lower discretionary intake of table salt and salt used in cooking ${ }^{(52)}$, but the most recent mean (95\% CI) UIC level of 131 $(122,141) \mathrm{ng} / \mathrm{ml}$ in the NHANES 2013-2014 data ${ }^{(47)}$ is still considered adequate from a population perspective. The WHO goals are that UIC levels should be $>100 \mathrm{ng} / \mathrm{ml}$ in $50 \%$ of the population and $<50 \mathrm{ng} / \mathrm{ml}$ in $<20 \%$ of the population ${ }^{(53)}$.

Like iron deficiency, iodine deficiency is a global health problem, but estimates based on WHO data and literature reviews suggest an overall worldwide improvement in iodine status from 2003 to $2011^{(54)}$. Nonetheless, there appeared to be a small increase in the prevalence of iodine deficiency over this period in the Americas ${ }^{(54)}$. Like iron deficiency, low iodine levels are of particular concern in military SM because of detrimental effects on muscle function and exercise capacity ${ }^{(55)}$ and adverse effects on work capacity ${ }^{(56)}$. Data in the present study suggest that iodine disorder rates are rising in military men but less so in military women. The fact that discretionary intake of salt is declining in the USA ${ }^{(52)}$ and clinically diagnosed iodine disorders are rising among military men suggests a more focused effort to ensure salt is fortified with iodine may be warranted. Further surveillance efforts will be needed to determine whether the increase in clinically diagnosed iodine disorders requires additional intervention.

\section{Strengths and limitations}

This study had the major advantage of examining the entire population of US SM over a period of 19 years using a database that included virtually all clinically diagnosed iron and iodine deficiencies. Deficiencies identified within military facilities were required to be entered into this database and medical personnel who diagnosed conditions outside military facilities were required to enter information into this database for reimbursement, assuring the database was inclusive. Nonetheless, there are limitations in the current analyses. Medical care provided by military unit medics in the field and at deployed locations may not be included in the DMED. However, it is unlikely that the nutritional conditions examined here would be diagnosed by medics who are primarily trained as first responders. Further, only healthy SM can be deployed and if a serious medical condition was detected in pre-deployment physicals, that individual would not deploy until the condition was treated. Another consideration is that this analysis was based on the primary diagnosis of the nutritional condition (first listed condition) in the DMED and thus may not account for comorbidities, pregnancies, dietary supplement use or other conditions that might affect these deficiencies. The DMED provides only the diagnosis (ICD-9 code) of a SM medical condition or the total number of visits for that medical condition (total encounters). If the nutritional condition (ICD-9 code) was listed in position other than the first (primary) because of a comorbid problem, that condition would not be included in this analysis. Thus, this analysis is limited to the nutritional conditions for which the diagnoses were 
the primary ones. Finally, these data should not be interpreted as reflecting the overall incidence rates of iron or iodine disorders in the military because not all (or a random sample) of SM were tested for the disorders. These data reflect rates at which mineral disorders were clinically diagnosed when a SM saw a medical care provider and that visit resulted in a mineral disorder documented in the medical record.

\section{Conclusions}

This study documents a relatively low incidence rate of clinically diagnosed iron and iodine deficiencies in the US Armed Forces. Nonetheless, rates for iron disorders increased substantially over time for both men and women. Iodine disorder rates rose steadily over time among men, while among women there were increases in the early years examined followed by a more recent gradual decline. Women had 10- to 12-fold higher incidence rates than men for both mineral disorders. Iron disorder rates were highest among the youngest ( $<20$ years old) and oldest $(\geq 40$ years old) male age groups, but iron deficiency rates increased steadily with age for both sexes. Compared with white SM, black SM had higher incidence rates for both iron and iodine deficiencies. The incidence rates reported here are for those individuals who were clinically diagnosed for these disorders and, as is the case for most diseases, the rates reported here undoubtedly underestimate the underlying incidence of the disorders.

While we are unaware of any other population-based data assessment of medical records to assess incidence of diagnosed dietary deficiencies and disorders, given advancement in digitised medical records and the desire to access and use large data sets, it is likely that such information could be available in the US population in the near future. As such, our results will be useful to those conducting these future analyses. Given the unexpected increases in incidence of the two mineral disorders examined that are associated with significant adverse health outcomes, greater surveillance of the military and civilian populations for these disorders may be appropriate.

\section{Acknowledgements}

Acknowledgements: Thanks to Patricia Bremner for assistance in acquiring some of the more difficult to obtain references and to the Defense Health Agency for assistance in obtaining data. Financial support: This work was supported by the Department of Defense Center Alliance for Nutrition and Dietary Supplements Research of the Defense Medical Research and Development Program. Conflict of interest: None. Authorship: J.J.K. contributed to study design, compiled the data, analysed the data, assisted in interpretation and wrote the paper; E.K.F. contributed to study design, assisted in interpretation and critically reviewed drafts of the paper; V.L.F. contributed to study design, assisted in interpretation and critically reviewed drafts of the paper; H.R.L. conceived the study, contributed to study design, assisted in interpretation and critically reviewed drafts of the paper. All authors have read and approved the manuscript. Ethics of human subject participation: The US Army Research Institute of Environmental Medicine Human Research Protection Office approved this retrospective analysis of de-identified data from the Defense Medical Epidemiological Database. Disclaimer: The opinions contained herein are the private views of the authors and are not to be construed as official or as reflecting the views of the Army or the Department of Defense. Citations of commercial organisations and trade names in this report do not constitute an official Department of the Army endorsement or approval of the products or services of these organisations. Approved for public release; distribution is unlimited.

\section{References}

1. Day DS, Young A \& Askew EW (2012) Nutrition and Military Performance. Military Quantitative Physiology: Problems and Concepts in Military Operational Medicine. Falls Church, VA: Bordon Institute.

2. Friedl KE \& Hoyt RW (1997) Development and biomedical testing of military operational rations. Ann Rev Nutr 17, 51-75.

3. Schnakenberg DD (1986) Military nutrition research - a brief history, 1917-1980. Nut Hist Notes 25, 1-4.

4. Pandolf KB, Francesconi R, Sawka MN et al. (2011) United States Army Research Institute of Environmental Medicine: Warfighter research focusing on the past 25 years. $A d v$ Physiol Educ 35, 353-360.

5. National Institute of Health (2020) Iron. Fact Sheet for Health Professionals. https://ods.od.nih.gov/factsheets/IronHealthProfessional/ (accessed April 2020).

6. Centers for Disease Control and Prevention (2012) Iodine levels in young women border of insufficiency. https:// www.cdc.gov/nutritionreport/pdf/Second-Nutrition-ReportIodine-Factsheet.pdf (accessed April 2012).

7. Knapik JJ, Jean RT, Austin KG et al. (2016) Temporal trends in dietary supplement prescriptions of United States military service members suggest a decrease in pyridoxine and increase in vitamin D supplements from 2005 to 2013. Nutr Res 36, 1140-1152.

8. Attipoe S, Jones DR, Olsen CH et al. (2015) Trends in mineral supplement prescriptions from military treatment facilities: 2007-2011. Milit Med 180, 742-747.

9. Knapik JJ, Jean RT, Austin KG et al. (2017) Demographic factors associated with dietary supplement prescriptions filled by United States military service members 2005-2013. BMC Complement Altern Med 17, 84.

10. Beard JL (2001) Iron biology in immune function, muscle metabolism and neuronal functioning. J Nutr 131, 568S-580S.

11. Gardner GW, Edgerton VR, Senewiratne B et al. (1977) Physical work capacity and metabolic stress in subjects with iron deficiency anemia. Am J Clin Nutr 30, 910-917.

12. McClung JP, Marchitelli LJ, Friedl KE et al. (2006) Prevalence of iron deficiency and iron deficiency anemia among three populations of female military personnel in the US Army. J Am Coll Nutr 25, 64-69. 
13. McClung JP, Karl JP, Cable SJ et al. (2009) Randomized, double-blind, placebo controlled trial of iron supplementation in female soldiers during military training: effects on iron status, physical performance, and mood. Am J Clin Nutr $\mathbf{9 0}$, 124-131.

14. Farina EK, Taylor JC, Means GE et al. (2017) Effects of deployment on diet quality and nutritional status markers of elite U.S. Army Special Operations Forces soldiers. Nutr $J$ 16, 41.

15. McClung JP, Karl JP, Bass LJ et al. (2011) Iron status declines in male soldiers during military training despite increased dietary iron intake. FASEB J 25, 607.

16. Zimmermann MB \& Boelaert K (2015) Iodine deficiency and thyroid disorders. Lancet Diabetes Endocrinol 3, 286-295.

17. Carle A, Krejbjerg A \& Laurberg P (2014) Epidemiology of goitre. Influence of iodine intake. Best Pract Res Clin Endocrinol Metab 28, 465-479.

18. Chaker L, Bianco AC, Jonklaas J et al. (2017) Hypothyroidism. Lancet 390, 1550-1562.

19. Stahlman S \& Oh GT (2018) Thyroid disorders, active component, U.S. Armed Forces, 2008-2017. MSMR 25, 2-9.

20. Dean AG, Sullivan KM \& Soe MM (2013) Open Source Epidemiologic Statistics for Public Health, Version 3.01. http://www.openepi.com/Menu/OE_Menu.htm (accessed March 2019).

21. Dallman PR (1986) Biochemical basis for the manifestations of iron deficiency. Ann Rev Nutr 6, 13-40.

22. Haas JD \& Brownlie T (2001) Iron deficiency and reduced work capacity: a critical review of the research to determine a causal relationship. J Nutr 131, 676S-690S.

23. World Health Organization (2001) Iron deficiency anaemia. Assessment, prevention and control. https://www.who.int/ nutrition/publications/en/ida_assessment_prevention_control. pdf (accessed June 2019).

24. 2016 Global Burden of Diseases and Injury Incidence and Prevalence Collaborators (2017) Global, regional, and national prevalence, and years lived with disability forb 328 diseases and injuries for 195 countries, 1990-2016: a systematic analysis for the Global Burden of Disease Study 2016 Lancet 390, 1211-1259.

25. Institute of Medicine (2000) Dietary Reference Intakes for Vitamin A, Vitamin K, Arsenic, Boron, Chromium, Copper, Iodine, Iron, Manganese, Molybdenum, Nikel, Silicon, Vanadium, and Zinc. Washington DC: National Academies Press.

26. Medical Surveillance Monthly Report (2012) Iron deficiency anemia, active component, U.S. Armed Forces, 2002-2011. MSMR 19, 17-21.

27. Martin NM, Conlon CA, Smeele RJM et al. (2019) Iron status and associations with physical performance during basic combat training in female New Zealand Army recruits. Br J Nutr 121, 887-893.

28. Israeli $\mathrm{E}$, Merkel $\mathrm{D}$, Constantini $\mathrm{N}$ et al. (2008) Iron deficiency and the role of nutrition among female military recruits. Med Sci Sports Exerc 40, S685-S690.

29. Epstein D, Borohovitz A, Merdler I et al. (2018) Prevalence of iron deficiency and iron deficiency anemia in strenuously training male Army recruits. Acta Hematol 139, 141-147.

30. Centers for Disease Control and Prevention (2012) Second national report on biochemical indicators of diet and nutrition in the U.S. population. https://www.cdc.gov/ nutritionreport/pdf/Nutrition_Book_complete508_final.pdf (accessed October 2019)

31. Scott SP \& Murry-Kolb LE (2015) Iron status is associated with performance on excutive functioning tasks in nonanemic young women. $J$ Nutr 146, 30-37.

32. Scott SP, Souza MJD, Koehler K et al. (2017) Combined iron deficiency and low aerobic fitness doubly burden academic performance among women attending university. J Nutr 147, 104-109.
33. Sharp MA, Patton JF \& Vogel JA (1998) A Database of Physically Demanding Tasks Performed by U.S. Army Soldiers. no. T98-12. Natick, MA: US Army Research Institute of Environmental Medicine.

34. Kirin SJ \& Winkler JD (1992) The Army Military Occupational Specialty Database. Santa Monica: The Rand Corporation.

35. Short MW \& Domagalski JE (2013) Iron deficiency anemia: evaluation and management. Am Fam Phys 87, 98-104.

36. Camaschella C (2015) Iron deficiency: new insights into diagnosis and treatment. Hematol Am Soc Hematol Educ Program 2015, 2018-2013.

37. Looker AC, Dallman PR, Carroll MD et al. (1997) Prevalence of iron deficiency in the United States. JAMA 277, 973-976.

38. Pearce EN \& Caldwell KL (2016) Urinary iodine, thyroid function, and thyroglobulin as biomarkers of iodine status. $\mathrm{Am} \mathrm{J}$ Clin Nutr 104, 898S-901S.

39. Knudsen N \& Brix TH (2014) Genetic and non-iodine-related factors in the aetiology of nodular goiter. Best Pract Res Clin Endocrinol Metab 28, 495-506.

40. Department of defense (DoD) (2018) DoD Instruction 6130.03, Medical standards for appointment, enlistment or induction into the military services. https://www.esd.whs. mil/Portals/54/Documents/DD/issuances/dodi/613003p.pdf? ver=2018-05-04-113917-883 (accessed June 2019).

41. Medical Surveillance Monthly Report (2012) Thyroid disorders among active component military members, U.S. Armed Forces, 2002-2011. MSMR 19, 7-10.

42. Li H (2015) Thyroid disorders in women. Minerva Med 106, 109-114.

43. Stahlman S \& Oetting AA (2018) Mental health disorders and mental health problems, active component, U.S. Armed Forces, 2007-2016. MSMR 25, 2-11.

44. Bialik K (2017) U.S. active duty military presence overseas is at its smallest in decades. https://www.pewresearch.org/ fact-tank/2017/08/22/u-s-active-duty-military-presenceoverseas-is-at-its-smallest-in-decades/ (accessed June 2010).

45. Hollowell JG, Staehling NW, Hannon H et al. (1998) Iodine nutrition in the United States. Trends, public health implications from the National Health and nutrition Examination Surveys I, III (1971-1974, 1998-1994). J Clin Endrocrinol Metabol 83, 3401-3408.

46. Caldwell KL, Jones R \& Hollowell JG (2005) Urinary iodine concentration: United States National Health and Nutrition Examination Survey 2001-2002. Thyroid 15, 692-699.

47. Corey LM, Bell GP \& Pleus RC (2017) Exposure of the US population to nitrate, thiocyanate, perchlorate, and iodine based on NHANES 2005-2014. Bull Environ Contam Toxicol 99, 83-88.

48. Caldwell KL, Makhmudov A \& Ely E et al. (2011) Iodine status of the U.S. population, National Health and Nutrition Examination Survey, 2005-2006 and 2007-2008. Thyroid 21, 419-427.

49. Herrick KA, Perrine CG, Aoki Y et al. (2018) Iodine status and consumption of key iodine sources in the U.S. population with special attention to reproductive age women. Nutrients 10, 874 .

50. Lee K, Bradley R, Dwyer J et al. (1999) Too much versus too little: the implications of current iodine intake in the United States. Nutr Rev 57, 177-181.

51. Pennington JAT \& Schoen SA (1996) Total diet study: estimated dietary intakes of nutritional elements 1982-1991. Int J Vit Nutr Res 66, 350-362.

52. Quader ZS, Patel S, Gillespie C et al. (2016) Trends and determinates of discretionary salt use: national Health and Nutrition Examination Survey 2003-2012. Public Health Nutr 19, 2195-2203.

53. World Health Organization (2007) Assessment of iodine deficiency disorders and monitoring their elimination. http:// 
whqlibdoc.who.int/publications/2007/9789241595827_eng. pdf (accessed January 2020).

54. Andersson M, Karumbunathan V \& Zimmermann MB (2012) Global iodine status in 2011 and trends over the past decade. J Nutr 142, 744-750.

55. Caraccio N, Natali A, Sironi A et al. (2005) Muscle Metabolism and exercise tolerance in subclinical hypothyroidism: a controlled trial of levothyroxine. J Clin Endrocrinol Metabol 90, 4057-4062.

56. Nexo MA, Watt T, Pedersen J et al. (2014) Increased risk of long-term sickness absence, lower rate of return to work and higher risk of unemployment and disability pensioning for thyroid patients: a Danish register-based cohort study. $J$ Clin Endrocrinol Metabol 99, 3184-3192. 